\title{
Antibody evidence of SARS-CoV-2 infection in healthcare workers in the Bronx
}

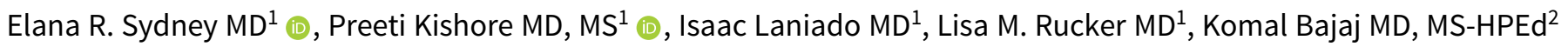 \\ and Michael J. Zinaman MD² \\ ${ }^{1}$ Department of Medicine, Jacobi Medical Center, Bronx, New York and ${ }^{2}$ Department of Obstetrics and Gynecology, Jacobi Medical Center, Bronx, New York
}

The first recorded case of coronavirus disease (COVID-19) in New York City was on March 1, 2020, and by May 5, there were 171,723 confirmed cases with 13,724 confirmed deaths. ${ }^{1}$ The Bronx had the highest rates of hospitalization and death related to COVID-19 compared to the other 4 boroughs in New York City. ${ }^{2}$

Jacobi Medical Center, one of 11 acute-care facilities in the NYC municipal hospital system, is a 457-bed level 1 trauma center located in the Bronx with 3,225 healthcare workers. We began testing symptomatic employees on March 16 using the nasopharyngeal polymerase chain reaction (PCR) severe acute respiratory coronavirus virus 2 (SARS-CoV-2) test. In the first 6 weeks, we tested 1,264 employees, of whom 302 tested positive (23.9\%). Recent reports showed that $12.2 \%$ of NYC healthcare workers had a confirmed positive SARS-CoV-2 PCR result. ${ }^{3}$

Preliminary data reveal that $19.9 \%$ of NYC residents have antibodies to SARS-CoV-2 virus, and $27.6 \%$ of Bronx residents have antibodies. Given this high prevalence of antibodies in the Bronx, we predicted that our staff would have higher prevalence of antibodies, especially those staff working in areas of perceived risk, such as the emergency department and critical care areas.

Once Abbott Labs (Abbott Park, IL) received the emergency use authorization for antibody testing using the SARS-CoV-2 IgG test, ${ }^{4}$ we began a voluntarily testing all employees at our facility. This test has a reported sensitivity of $100 \%$ and specificity of $99.6 \%$ when performed 2 weeks after symptom onset. ${ }^{5}$ Individuals were offered the IgG test as long as they were asymptomatic and had not had COVID-19 symptoms during the prior 2 weeks.

A retrospective chart review was performed to answer the following questions:

1. Were there demographic differences among antibodypositive healthcare workers?

2. What departments had the highest number of positive antibody tests?

3. What is the prevalence of antibody positivity in symptomatic healthcare workers?

4. How many of the asymptomatic healthcare workers developed antibodies?

Author for correspondence: Elana R. Sydney E-mail: elana.sydney@nychhc.org Cite this article: Sydney ER, et al. (2020). Antibody evidence of SARS-CoV-2 infection in healthcare workers in the Bronx. Infection Control \& Hospital Epidemiology, 41: 1348-1349, https://doi.org/10.1017/ice.2020.437
5. What is the prevalence of antibodies in those healthcare workers with self-reported positive and negative SARS-CoV-2 PCR tests?

Data were extracted from the electronic medical record and were deidentified for analysis. In total, 1,700 healthcare workers were tested for SARS-CoV-2 IgG antibody between April 28 and May 4, 2020. We analyzed the data by looking at those healthcare workers that had positive antibodies and stratified it based on department, presence or absence of symptoms, and previously reported positive PCR.

Of the 1,700 individuals tested, SARS-CoV-2 IgG antibodies were detected in 327 individuals (19\%). Among them, 221 healthcare workers with positive antibodies $(67.6 \%)$ were women. The mean age of those that tested positive was 44 years (range, 22-73). The percentage of African-American healthcare workers that tested positive for antibodies was $27.2 \%$. This was statistically significant compared to other racial groups that tested positive $(P<.05)$. The highest prevalence ( $26 \%$ presence of IgG) was detected in the emergency department and the behavioral health department (Table 1). The behavioral health department included the psychiatric emergency room and inpatient and outpatient psychiatry. Suprisingly, the lowest prevalence was found in critical care staff, with $11 \%$ testing positive.

More than half (53\%) of the individuals tested reported having symptoms suggestive of COVID-19. Of these healthcare workers, $28 \%$ showed the presence of IgG antibody, and $9 \%$ of asymptomatic healthcare workers had IgG antibodies. Notably, $12 \%$ of those who tested positive for the presence of IgG reported a negative SARSCoV-2 PCR result. As expected, $92 \%$ of individuals that reported a positive PCR test developed IgG antibodies. A small number of individuals, representing $1 \%$ of those reporting a positive SARS-CoV-2 PCR test prior to being tested, had a negative antibody test. This finding is consistent with a previous report from China in which a small number of patients with COVID-19 did not develop antibodies. ${ }^{6}$

Our results reflect a higher overall rate of SARS-CoV-2 antibody development among healthcare workers in the Bronx compared to reported rates in NYC healthcare workers. ${ }^{3}$ However, the rates were lower than the reported Bronx community prevalence. ${ }^{4}$ This finding is not unexpected because hospital staff had better access to protective equipment than did the general population as well as a heightened awareness of the seriousness of the infection. Based on our findings, hospitals with psychiatric services, especially with psychiatric emergency departments, should consider increasing the use of SARSCoV-2 transmission prevention resources. Our African-American healthcare workers had a significant difference in antibody positivity. This finding needs to be confirmed in a larger study, and additional 
Table 1. Results of Antibody Positivity by Department, Presence or Absence of Symptoms and Reported Negative PCR Test

\begin{tabular}{|c|c|c|c|c|c|c|c|c|}
\hline \multirow[b]{2}{*}{ Department } & \multirow[b]{2}{*}{ Total } & \multirow[b]{2}{*}{ Positive IgG (\%) } & \multicolumn{2}{|c|}{ Symptomatic } & \multicolumn{2}{|c|}{ Asymptomatic } & \multicolumn{2}{|c|}{$\begin{array}{c}\text { Symptomatic Negative } \\
\text { PCR } \\
\end{array}$} \\
\hline & & & Total & Positive IgG (\%) & Total & Positive IgG (\%) & Total & Positive IgG (\%) \\
\hline Behavioral health/Psychiatry & 104 & $27(26)$ & 65 & $22(34)$ & 39 & $5(13)$ & 65 & $16(25)$ \\
\hline Critical care/ICU & 418 & $47(11)$ & 201 & $36(18)$ & 217 & $11(5)$ & 201 & $13(6)$ \\
\hline Not applicable & 26 & $10(38)$ & 12 & $6(50)$ & 14 & $4(29)$ & 12 & $3(25)$ \\
\hline OB/Gyn & 81 & $15(19)$ & 38 & $12(32)$ & 43 & $3(7)$ & 38 & $3(8)$ \\
\hline Other healthcare worker & 296 & $61(21)$ & 137 & $41(30)$ & 159 & 20(13) & 137 & $16(12)$ \\
\hline Trauma service & 15 & 2(13) & 12 & $2(17)$ & 3 & $0(0)$ & 12 & $1(8)$ \\
\hline
\end{tabular}

Note. PCR, polymerase chain reaction; ICU, intensive care unit; OB/Gyn, obstetrics and gynecology.

investigation is necessary to understand the reasons for this finding. The low rate of antibody development in critical care areas could be explained by the controlled environment and lower volume compared to other areas. Finally, 12\% of hospital staff who developed antibodies in spite of a negative PCR test could be explained by false-negative PCR testing, infection after the PCR test, or inaccurate self-report.

It is unclear whether the presence of IgG antibodies confers longterm immunity. Emphasis is being placed on antibody testing for reopening the economy and return-to-work policies. ${ }^{7,8}$ However, only 1 in 5 healthcare workers developed antibodies during the peak of the pandemic at our hospital; thus, the utility of antibody testing to guide staffing considerations is limited. Ultimately, development of prophylactic treatments and therapies for COVID-19 is needed to ensure the safety of our healthcare workers pending the arrival of a vaccine.

Acknowledgments. We acknowledge the contribution of Mr. Ryan Fraleigh in the data analysis of this manuscript.

Financial support. No financial support was provided relevant to this article.

Conflicts of interest. All authors report no conflicts of interest relevant to this article.
2. Wadhera RK, Wadhera P, Gaba P, et al. Variation in COVID-19 hospitalizations and death across New York City boroughs. JAMA 2020;323:2192-2195.

3. Amid ongoing COVID-19 pandemic, Governor Cuomo announces moratorium on COVID-related evictions will be extended until August 20. Governor Andrew Cuomo website. https://www.governor.ny.gov/news/ amid-ongoing-covid-19-pandemic-governor-cuomo-announces-moratoriumcovid-related-evictions-will. Published May 7, 2020. Accessed August 25, 2020.

4. EUA authorized serology test performance. US Food and Drug Administration website. https://www.fda.gov/medical-devices/emergency-situations-medicaldevices/eua-authorized-serology-test-performance. Updated August 17, 2020. Accessed August 25, 2020.

5. Bryan A, Pepper G, Wener MH, et al. Performance characteristics of the Abbott Architect SARS-CoV-2 IgG assay and seroprevalence testing in Idaho. Medrxiv 2020. doi: 10.1101/2020.04.27.20082362v1.

6. Long Q, Liu B, Deng H, et al. Antibody responses to SARS-CoV-2 in patients with COVID-19. Nat Med 2020;26:845-848.

7. Beeching Nick J, Fletcher Tom E, Beadsworth Mike BJ. Covid-19: testing times BMJ 2020 Apr 8. doi: 10.1136/bmj.m1403.

8. Abbasi J. The promise and peril of antibody testing for COVID-19. JAMA 2020;323:1881-1883.

\title{
References
}

1. COVID-19 data. NYC Health website. https://www1.nyc.gov/site/doh/covid/ covid-19-data.page. Accessed May 5, 2020.

\section{Nudging empiric prescribing: Embedding antimicrobial stewardship program order sets into a general medicine admission order set}

\author{
April J. Chan PharmD ${ }^{1}$ (1), Ajay Kapur MD ${ }^{1}$, Bradley J. Langford PharmD² and Mark Downing MD ${ }^{1,3}$ \\ ${ }^{1}$ St Joseph's Health Centre, Unity Health Toronto, ON, Canada, ${ }^{2}$ Ontario Agency for Health Protection and Promotion, ON, Canada and ${ }^{3}$ University of Toronto, \\ ON, Canada
}

Author for correspondence: April J Chan, E-mail: apriljane.chan@gmail.com. PREVIOUS PRESENTATION. This study was presented as a poster at IDWeek 2019 on October 5, 2019, in Washington, DC.

Cite this article: Chan AJ, et al. (2020). Nudging empiric prescribing: Embedding antimicrobial stewardship program order sets into a general medicine admission order set. Infection Control \& Hospital Epidemiology, 41: 1349-1351, https://doi.org/10.1017/ ice. 2020.346
The use of facility-specific clinical practice guidelines and clinical decision-making tools are recommended as part of an antimicrobial stewardship program (ASP). ${ }^{1}$ Clinical decision-making tools are diverse and can include complex computer algorithms, checklists, and electronic order sets. ${ }^{2}$ They have been shown to improve adherence to evidence-based antibiotic prescribing, reducing unnecessary antibiotic use $\mathrm{u}^{2-5}$ and improving appropriateness of 